\title{
Husbands' perceptions of their wives' breast cancer coping efficacy: testing congruence models of adjustment
}

This article was published in the following Dove Press journal:

Cancer Management and Research

\author{
Thomas V Merluzzi' \\ MaryAnn Martinez Sanchez ${ }^{2}$ \\ 'Department of Psychology, University \\ of Notre Dame, Notre Dame, IN, \\ ${ }^{2}$ Pima Community College, Tucson, \\ AZ, USA
}

Introduction: Recent reviews have reinforced the notion that having a supportive spouse can help with the process of coping with and adjusting to cancer. Congruence between spouses' perspectives has been proposed as one mechanism in that process, yet alternative models of congruence have not been examined closely. This study assessed alternative models of congruence in perceptions of coping and their mediating effects on adjustment to breast cancer.

Methods: Seventy-two women in treatment for breast cancer and their husbands completed measures of marital adjustment, self-efficacy for coping, and adjustment to cancer. Karnofsky Performance Status was obtained from medical records. Wives completed a measure of selfefficacy for coping (wives' ratings of self-efficacy for coping [WSEC]) and husbands completed a measure of self-efficacy for coping (husbands' ratings of wives' self-efficacy for coping [HSEC]) based on their perceptions of their wives' coping efficacy.

Results: Interestingly, the correlation between WSEC and HSEC was only 0.207 ; thus, they are relatively independent perspectives. The following three models were tested to determine the nature of the relationship between WSEC and HSEC: discrepancy model (WSEC - HSEC), additive model (WSEC + HSEC), and multiplicative model (WSEC $\times$ HSEC). The discrepancy model was not related to wives' adjustment; however, the additive $(B=0.205, P<0.001)$ and multiplicative $(B=0.001, P<0.001)$ models were significantly related to wives' adjustment. Also, the additive model mediated the relationship between performance status and adjustment. Discussion: Husbands' perception of their wives' coping efficacy contributed marginally to their wives' adjustment, and the combination of WSEC and HSEC mediated the relationship between functional status and wives' adjustment, thus positively impacting wives' adjustment to cancer. Future research is needed to determine the quality of the differences between HSEC and WSEC in order to develop interventions to optimize the impact of these two relatively independent perspectives on cancer outcomes.

Keywords: couples, cancer, coping, adjustment, self-efficacy

\section{Plain language summary}

This research was conducted to test the assumption that couples should not have major differences in their perspectives on coping; that is, the spouse with cancer and the caregiving spouse should not be far apart in their perceptions of how the spouse with cancer is coping and adjusting to cancer. Wives with breast cancer and their husbands completed measures of coping and adjustment. The findings indicate that couples may not have exactly the same perspective on coping but rather combine different but complementary perspectives. That is, the higher the level of their combined perspectives on coping, the greater the level of adjustment for the spouse with cancer.
Correspondence: Thomas V Merluzzi Department of Psychology, I2I Haggar Hall, University of Notre Dame, Notre Dame, IN 46556, USA

Tel +I 57463 I 5623

Email tmerluzz@nd.edu 


\section{Introduction}

Recent reviews have reinforced the notion that having a supportive spouse and positive marital relationship can help with the process of coping with and adjusting to cancer. ${ }^{1-3}$ Several conceptual labels have been attached to types of couples' coping processes: ${ }^{3}$ relationship-focused coping, ${ }^{4}$ positive dyadic coping, ${ }^{5,6}$ collaborative coping, ${ }^{7}$ communal coping, ${ }^{8,9}$ and congruency coping. ${ }^{10-12}$ The underlying theme in this research is that congruence or alliance between spouses is important in the process of managing physical and emotional challenges in all phases of the cancer trajectory. And, whereas congruence is the main theme, there has been little testing of varying models of coping congruence.

Support for coping congruence is based on couples using "similar or complementary coping styles", ${ }_{3}^{3}$ which result in better adjustment for the spouse with cancer. Alternatively, discrepancies in coping can lead to distress and poor adjustment to cancer. For example, Ben-Zur et al ${ }^{12}$ found that greater discrepancies in the use of emotion-focused coping between cancer patients and their partners resulted in distress and adjustment problems. Thus, not only discrepancies in the use of a particular coping behavior may be a problem, but perhaps also differences in the level or overall coping capacity lead to negative outcomes. This extension of congruency theory is the focus of the current study.

Romero et $\mathrm{al}^{13}$ provide an interesting example of the effects of discrepancies by focusing on the congruence of husbands' and wives' perceptions of wives' adjustment to cancer and the impact of that congruence on wives' functioning, in this case mood disturbance. They found that the greater the incongruence of husbands' and wives' perceptions of the wives' adjustment to cancer, the greater the wives' mood disturbance, that is, negative mood state. This approach to congruence, though not focused on coping, assumes a singular model of congruence that consists of an absolute difference between husbands' and wives' perceptions. However, other models may be predictive of distress or quality of life outcomes such as additive (complementary) and multiplicative models. While the discrepancy approach to the congruence model assumes that the greater the discrepancy between spouses' perspectives the more negative the outcome, the additive model assumes that the husbands' perspective may provide an independent contribution that may add positively to wives' perceptions in relation to outcomes. Also, the multiplicative model assumes that there is a synergy between the husbands' and wives' perceptions, such that there is an exponential effect of combining their perceptions.
The current study builds upon congruency theory and Romero et $\mathrm{a}^{13}$ in three ways. First, as opposed to congruence in perceptions of adjustment, the current study investigated congruence in perceptions of coping. Second, this study tested alternative models of congruence, that is, not just the discrepancy model but also additive and multiplicative models. Third, instead of testing the relationship of congruence with mood disturbance as in Romero et al, the current study investigated husbands' perceptions of their wives' coping efficacy and wives' perceptions of their coping efficacy in relation to adjustment to cancer. Thus, the three coping models, discrepancy, additive, and multiplicative, were tested in relation to adjustment to cancer. Also, as in Romero et al, ${ }^{13}$ the current study investigated husbands' and wives' perceptions in a mediating role. In this study, the three congruence models were investigated as potential mediators in the relationship between performance status (ie, level of functioning) and adjustment.

\section{Methods}

\section{Participants}

One hundred twenty-six women with breast cancer were recruited for participation in this research from the following two sites: a hospital-based regional cancer center and a large private practice oncology clinic. That number represented a $65 \%$ participation rate. The breast cancer patients were asked if their partners or spouses would participate. Of the 126 women, 72 had partners who also volunteered to take part in the research. Thus, the final sample consisted of the 72 female breast cancer patients, all of whom were married to male partners. Same-sex couples or couples who were not married were not excluded from the sample but were not represented among the 72 couples who volunteered. All participants provided written consent.

During the course of the study, the patients provided demographic and disease-related information. In addition, information on staging at diagnosis, performance status, treatments received, and other pertinent data was obtained from medical records with the consent of the patients. Husbands signed a separate consent form, provided demographic information about themselves, and completed a questionnaire concerning their judgments of their wives' coping. Demographic and disease-related information on the 72 patients and their spouses is listed in Tables 1 and 2.

\section{Materials}

\section{Marital adjustment}

Marital adjustment was assessed by the Locke-Wallace Marital Adjustment Test (LWMAT). This measure was used 
Table I Demographic and disease-related information of wives with breast cancer $(\mathrm{N}=72)$

\begin{tabular}{|c|c|}
\hline \multicolumn{2}{|c|}{ Employment status (\%) } \\
\hline Employed & 43.7 \\
\hline Unemployed & 2.8 \\
\hline Retired & 22.5 \\
\hline Homemaker & 23.9 \\
\hline On leave & 1.4 \\
\hline Did not report & 5.7 \\
\hline \multicolumn{2}{|c|}{ Household income, US\$ (\%) } \\
\hline$<\$ 15,000$ & 16.9 \\
\hline$\$ 15,000-24,999$ & 14.1 \\
\hline$\$ 25,000-40,000$ & 32.4 \\
\hline$>\$ 40,000$ & 32.4 \\
\hline Did not report & 4.2 \\
\hline \multicolumn{2}{|l|}{ Education level (\%) } \\
\hline Grade school diploma & 1.4 \\
\hline Some high school & 9.7 \\
\hline High school diploma & 50.0 \\
\hline Some college & 15.3 \\
\hline College degree & 6.9 \\
\hline Some graduate work & 6.9 \\
\hline Graduate degree & 5.7 \\
\hline \multicolumn{2}{|c|}{ Religious preference (\%) } \\
\hline Protestant & 56.3 \\
\hline Catholic & 28.2 \\
\hline Other & 14.1 \\
\hline Did not report & 1.4 \\
\hline \multicolumn{2}{|l|}{ Race (\%) } \\
\hline Caucasian & 91.5 \\
\hline African American & 4.2 \\
\hline Native American & $\mathrm{I} .4$ \\
\hline Did not report & 2.9 \\
\hline \multicolumn{2}{|l|}{ Treatments (\%) } \\
\hline Surgery & 87.3 \\
\hline Radiation & 9.9 \\
\hline Chemotherapy & 67.6 \\
\hline \multicolumn{2}{|l|}{ Stage at diagnosis (\%) } \\
\hline Stage I & 36.6 \\
\hline Stage II & 29.6 \\
\hline Stage III & 1.4 \\
\hline Stage IV & 31.0 \\
\hline Other & 1.4 \\
\hline \multicolumn{2}{|l|}{ Metastatic disease (\%) } \\
\hline Yes & 32.4 \\
\hline No & 67.6 \\
\hline \multicolumn{2}{|l|}{ Age (years) } \\
\hline Mean & 55 \\
\hline Range & $30-86$ \\
\hline \multicolumn{2}{|c|}{ Months since diagnosis } \\
\hline Mean & 36.16 \\
\hline Range & $6-140$ \\
\hline
\end{tabular}

Note: For treatments, more than one response was possible.

in some analyses as a covariate. The LWMAT is a 15 -item measure designed as a global measure of marital happiness. Internal consistency of the LWMAT has been estimated to be 0.90 , and criterion validity has been established with the
Table 2 Demographic information obtained from husbands $(\mathrm{N}=72)$

\begin{tabular}{ll}
\hline Employment status (\%) & 64.8 \\
Employed & 4.2 \\
Unemployed & 28.2 \\
Retired & 1.4 \\
Homemaker & 1.4 \\
Did not report & \\
Education level (\%) & 2.8 \\
Grade school diploma & 7.0 \\
Some high school & 31.0 \\
High School diploma & 32.4 \\
Some college & 5.6 \\
College degree & 5.6 \\
Some graduate work & 14.1 \\
Graduate degree & 1.5 \\
Did not report & \\
Religious preference (\%) & 53.5 \\
Protestant & 33.8 \\
Catholic & 11.3 \\
Other & 1.4 \\
Did not report & \\
Race (\%) & 91.5 \\
Caucasian & 4.2 \\
African American & 1.5 \\
Other & 2.8 \\
Did not report & \\
Age (years) & 56 \\
Mean & $26-84$ \\
Range &
\end{tabular}

scores discriminating between adjusted and maladjusted couples. ${ }^{14}$

\section{Self-efficacy for coping}

The Cancer Behavior Inventory ${ }^{15}$ (CBI) is a measure of self-efficacy for coping with cancer. The 51 original items of the CBI were used in this study. Following each item is a Likert-type scale, ranging from 1 (not at all confident) to 9 (totally confident), assessing the patient's confidence that she can accomplish each item. Cronbach's $a$ for the total score of wives (wives' ratings of self-efficacy for coping [WSEC]) was 0.95 . A version of the CBI was created for the husbands (husbands' ratings of wives' self-efficacy for coping [HSEC]) in which they were asked to rate how confident they (the husbands) were that their wives (the patients) could accomplish each coping behavior. Cronbach's $a$ for the HSEC was 0.95 .

\section{Performance status}

Karnofsky Performance Status ${ }^{16}$ (KPS) ratings were used as an indicator of the general functioning level of the patient. KPS scores range from $0 \%$ (dead) to $100 \%$ (normal with no complaints). The KPS has reliably discriminated between clinical populations such as pain patients, stroke 
patients, dialysis patients, and both medical and psychiatric outpatients. ${ }^{17}$ Nurses or physicians completed the KPS ratings on each of the patients.

\section{Adjustment}

A composite adjustment variable was created by combining scores from the Mental Health Index (MHI) and the Psychosocial Adjustment to Illness Scale (PAIS). The MHI ${ }^{18}$ is a 38-item indicator of psychological distress and well-being in the general population. The internal consistency estimates are 0.95 for psychological distress, 0.93 for psychological well-being, and 0.97 for the overall scale. The PAIS-SelfReport ${ }^{19}$ is a 46 -item scale that measures adjustment to illness. Each item is rated on a 4-point scale based on the patients' perceptions of changes in their adjustment over the previous 30-day period. Cronbach's $a$ for the entire scale was 0.91. Combining the MHI and PAIS provides a more robust composite measure of adjustment than single measure. It is tantamount in the measurement model in structural equation modeling to including multiple measures (ie, multiple manifest measures) of a latent variable. Thus, a composite measure is more robust and content valid than a single measure. Because the correlation between the two measures was significant and not close to unity (correlation of the MHI and PAIS $=0.647$ ), the composite effect was optimized because the measures do not exactly replicate one another.

\section{Procedure}

During their regular visits to the oncology clinic or the radiation oncology center, patients were approached by research nurses, with the permission of the treating physician, and asked if they would like to participate in a research project exploring coping with breast cancer. Upon agreeing to participate, informed consent was procured from the patient. The patient was given a booklet containing the measures described previously as well as a form requesting demographic and medical information to complete. A research assistant was present to answer questions and to collect completed data. The entire procedure took 90 minutes to complete.

Husbands were asked to complete a questionnaire about their wives' coping; that is, they provided their judgments of their wife's coping efficacy. They completed the materials separately from their wives. The procedure for the husband took $\sim 15$ minutes to complete. If the husband did not accompany his wife, she was asked to give him an informed consent form. When she returned the signed form, the husband was interviewed by telephone by a research assistant. Twenty of the spouses participated via the telephone interview procedure.

\section{Data analysis strategy}

Because of the small sample and the single measure for coping, bias reducing, bootstrap resampling ${ }^{20}$ was used in all regression analyses. Essentially, a regression coefficient (parameter estimate) was computed in the usual fashion, then, 1,000 resamplings with replacement were derived, and for each subsample, a parameter estimate was computed. A distribution was formed with all 1,000 parameter estimates, and a $95 \%$ CI was computed. If the $95 \%$ CI included 0 , then the original parameter estimate was determined to be not different from 0 (ie, not statistically significant). SPSS statistical software was used for all analyses.

\section{Ethics approval}

The study was approved by the University of Notre Dame Human Subjects' Institutional Review Board and the IRB of Memorial Hospital of South Bend. All participants provided written informed consent and were treated in accordance with the Ethical Principles of Psychologists and Code of Conduct of the American Psychological Association and the principles of the Health Information Portability and Accountability Act.

\section{Results \\ Model testing}

The WSEC and the HSEC were modestly correlated $(r=0.207)$, indicating that wives and husbands, for the most part, had their own unique perspectives on wives' coping. Thus, with respect to the construct of coping efficacy, investigating discrepancies may not be warranted as WSEC and HSEC scores shared only $\sim 4 \%$ common variance. In spite of these conceptual issues, the discrepancy model was tested with the measure of discrepancy used by Romero et al, which was the absolute difference between WSEC and HSEC. A conservative approach to model testing was taken, by controlling a number of variables that may account for variance in the dependent variable, adjustment (MHI + PAIS). Confirming that WSEC and HSEC are somewhat different constructs, there was no relationship between the discrepancy score and wives' adjustment to cancer $(B=0.089,95 \%$ CI: $-0.032,0.237)$ controlling for age, income, education, marital adjustment (LWMAT), KPS, and stage, although the overall regression was significant $\left(R^{2}=0.274, F=3.45\right.$, $P=0.003$ ).

As an alternative to absolute differences, discrepancy was otherwise defined as the husbands' tendency to over- or underestimate their wives' coping efficacy. Husbands were divided into the following two groups: "underestimators", whose 
HSEC scores were lower than their wives' WSEC scores, and "overestimators", whose HSEC scores were higher than their wives' WSEC scores. There were no statistical differences between underestimators $(M=327.03 ; \mathrm{SD}=34.95 ; \mathrm{n}=31)$ and overestimators $(M=339.89 ; \mathrm{SD}=34.52 ; \mathrm{n}=41)$ on the measure of wives' adjustment (MHI + PAIS). Thus, without intervention, there appear to be little congruence between wives' and husbands' perceptions of wives' coping efficacy and no differential effects of discrepancies that represent over- or underestimating wives' coping efficacy relative to the wives' scores.

As opposed to the discrepancy model, the additive model (WSEC + HSEC) and the multiplicative model (WSEC $\times$ HSEC) were significantly related to wives' adjustment (MHI + PAIS) scores ( $B=0.206,95 \%$ CI: 0.105, 0.325; $B=0.001,95 \%$ CI: $0.000,0.001$, respectively), controlling for age, income, education, marital adjustment (LWMAT), KPS, and stage. The overall regressions were significant for the additive $\left(R^{2}=0.397, F=6.013, P<0.000\right)$ and multiplicative models $\left(R^{2}=0.385, F=5.724, P<0.000\right)$. These results indicate that the critical issue in relating coping to adjustment is not discrepancy but perhaps the combination of husbands' and wives' coping efficacy ratings, essentially, more is better. Moreover, the correlation between the additive and multiplicative model scores was close to unity ( $r=0.996, P=0.001)$, indicating that they were identical. For the sake of parsimony, the additive model was selected for subsequent analyses.

In order to test, in the additive model, whether husbands' perceptions (HSEC) add variance to the prediction of wives' adjustment over-and-above the variance that is determined by the wives' reports of their own coping efficacy (WSEC), a regression analysis was computed controlling for age, income, education, marital adjustment (LWMAT), KPS, and stage. This analysis, in which WSEC $(B=0.282,95 \%$ CI: $0.130,0.469)$ was entered before HSEC ( $B=0.123,95 \%$ CI: $-0.046,0.367)$, confirmed that HSEC contributed an increment of $2.3 \%$ in variance accounted for in wives' scores on adjustment to cancer (MHI + PAIS). However, the $B$ for HSEC had a $95 \%$ CI that contained 0 and the contribution was quite small. Thus, the dominant contribution to variance in the wives' adjustment was the wives' WSEC scores. Collectively, these data would indicate that the discrepancy model was not confirmed, whereas the additive model was confirmed that the husbands' contribution to the wives' adjustment was quite small.

\section{Mediation analyses}

In order to examine more complex models, two mediation models were tested based on the results of the additive model and the small increment based on HSEC scores. The first model tested the mediation effects of the additive model in the relationship between the functional status (KPS) of the wives and their adjustment to cancer (MHI + PAIS). The second model tested incremental effects of HSEC in a mediation model that included WSEC and HSEC as dual mediators of the relationship between KPS and wives' adjustment to cancer. All analyses were conducted controlling for age, income, education, marital adjustment (LWMAT), KPS, and stage.

\section{Additive model mediation}

The relationship between KPS and adjustment was fully mediated (Table 3 ) by the additive model (WSEC + HSEC). The direct effect of functional status (KPS) in the presence of the mediator was not significant ( $B=0.425,95 \% \mathrm{CI}:-0.753$, 1.293); however, the indirect mediated effects were statistically significant ( $B=0.009,95 \% \mathrm{CI}: 0.001,0.030)$. Thus, the combination of wives' and husbands' coping scores was a significant mediator and a proximal predictor of wives' adjustment supplanting the significant direct relationship between performance status and adjustment when the mediator was absent.

\section{Incremental mediation}

Based on the stringent model testing presented earlier in which the husbands' contribution to wives' adjustment was small, a mediation model was tested to determine if WSEC and HSEC mediated the relationship between KPS and adjustment (MHI + PAIS). When WSEC and HSEC were included as separate mediators (Table 4) in the relationship between KPS and adjustment, the KPS $\rightarrow$ adjustment relationship was reduced to nonsignificance $(B=0.574,95 \%$ CI: $-0.339,1.081)$. In addition, the total indirect mediation effects of both WSEC ( $B=0.021,95 \% \mathrm{CI}: 0.004,0.050)$ and HSEC ( $B=0.008,95 \%$ CI: $0.000,0.044)$ were statistically significant, indicating full mediation of WSEC and HSEC in the incremental mediation model. These results support the small but incremental value of the husbands' perspective on coping to their wives' adjustment to cancer and the importance of these perspectives in superseding the direct impact of functional status on wives' adjustment to cancer.

\section{Exploratory analyses}

Based on the low correlation between WSEC and HSEC, we explored the idea that there were differences between husbands and wives with respect to potential variables that may inform their ratings of coping efficacy. Although it is speculative and worthy of future research, based on correlational 
Table 3 Aggregated (WSEC + HSEC) adjustment outcome mediation model: parameter estimates, SE, and bootstrapped $95 \%$ Cls

\begin{tabular}{|c|c|c|c|c|c|}
\hline Path & Model parameter & Estimate & SE & $2.5 \%$ & $97.5 \%$ \\
\hline $\mathrm{al}^{\mathrm{a}}$ & $\mathrm{KPS} \rightarrow$ WSEC + HSEC & 0.044 & 0.019 & 0.007 & 0.086 \\
\hline $\mathrm{a} 2^{\mathrm{a}}$ & WSEC + HSEC $\rightarrow$ MHI/PAIS & 0.206 & 0.059 & 0.118 & 0.354 \\
\hline $\mathrm{cl}^{\mathrm{a}}$ & $\mathrm{KPS} \rightarrow \mathrm{MHI} / \mathrm{PAIS}$ & 0.888 & 0.446 & 0.108 & 1.766 \\
\hline $\mathrm{al} \times \mathrm{a}^{\mathrm{a}}$ & $\mathrm{KPS} \rightarrow \mathrm{WSEC}+\mathrm{HSEC} \times$ WSEC $+\mathrm{HSEC} \rightarrow \mathrm{MHI} / \mathrm{PAIS}$ & 0.009 & 0.001 & 0.001 & 0.030 \\
\hline c2 & $\mathrm{KPS} \rightarrow \mathrm{MHI} / \mathrm{PAIS}$ & 0.425 & 0.513 & -0.753 & 1.293 \\
\hline
\end{tabular}

Notes: SE, average standard error based on bootstrap resampling. $\mathrm{cl}$, direct path without mediating variables; c2, direct path in the mediated model; al $\times$ a2, indirect (mediation) effects. $R^{2}$ for full model $=0.415 ; F=5.59 I, P<0.000$. aSignificant parameter estimate.

Abbreviations: HSEC, husbands' ratings of wives' self-efficacy for coping; KPS, Karnofsky Performance Status; MHI, Mental Health Index; PAIS, Psychosocial Adjustment to Illness Scale; WSEC, wives' ratings of self-efficacy for coping.

Table 4 Separate WSEC and HSEC adjustment outcome mediation model: parameter estimates, SEs, and bootstrapped $95 \%$ Cls

\begin{tabular}{|c|c|c|c|c|c|}
\hline Path & Model parameter & Estimate & SE & $2.5 \%$ & $97.5 \%$ \\
\hline $\mathrm{al}^{\mathrm{a}}$ & KPS $\rightarrow$ WSEC & 0.057 & 0.029 & 0.009 & 0.101 \\
\hline bl & $\mathrm{KPS} \rightarrow \mathrm{HSEC}$ & 0.030 & 0.035 & -0.037 & 0.100 \\
\hline $\mathrm{a} 2^{\mathrm{a}}$ & WSEC $\rightarrow$ MHI/PAIS & 0.282 & 0.085 & 0.132 & 0.465 \\
\hline b2 & $\mathrm{HSEC} \rightarrow \mathrm{MHI} / \mathrm{PAIS}$ & 0.123 & 0.092 & -0.040 & 0.332 \\
\hline $\mathrm{cl}^{\mathrm{a}}$ & $\mathrm{KPS} \rightarrow \mathrm{MHI} / \mathrm{PAIS}$ & 0.888 & 0.446 & 0.108 & 1.766 \\
\hline $\mathrm{al} \times \mathrm{a}^{\mathrm{a}}$ & $\mathrm{KPS} \rightarrow$ WSEC $\times$ WSEC $\rightarrow$ MHI/PAIS & 0.016 & 0.002 & 0.001 & 0.047 \\
\hline $\mathrm{bl} \times \mathrm{b} 2^{\mathrm{a}}$ & $\mathrm{KPS} \rightarrow \mathrm{HSEC} \times \mathrm{HSEC} \rightarrow \mathrm{MHI} / \mathrm{PAIS}$ & 0.004 & 0.003 & 0.000 & 0.032 \\
\hline c2 & $\mathrm{KPS} \rightarrow \mathrm{MHI} / \mathrm{PAIS}$ & 0.379 & 0.507 & -0.717 & 1.288 \\
\hline $\mathrm{al} \times \mathrm{a} 2+\mathrm{bl} \times \mathrm{b2}^{\mathrm{a}}$ & Total indirect effects & 0.020 & 0.005 & 0.001 & 0.079 \\
\hline
\end{tabular}

Notes: SE, average standard error based on bootstrap resampling. cl, direct path without mediating variables; c2, direct path in the mediated model; al $\times$ a2, indirect (mediation) effects for wives coping scores; b $\times$ b2, indirect (mediation) effects for husbands' coping scores. $R^{2}$ for full model $=0.397 ; F=6.03 \mathrm{I}, P<0.000$. ${ }^{2}$ Significant parameter estimate.

Abbreviations: HSEC, husbands' ratings of wives' self-efficacy for coping; KPS, Karnofsky Performance Status; MHI, Mental Health Index; PAIS, Psychosocial Adjustment to Illness Scale; WSEC, wives' ratings of self-efficacy for coping.

evidence, it appears that husbands' scores (HSEC) may be influenced by medical data to a greater extent than wives' scores (WSEC). Perhaps wives made judgments about coping that were based more on internal states, whereas husbands may have relied on other sources that are more accessible, such as medical data. That conclusion was based on correlations of WSEC and HSEC scores, respectively, with physicianprovided ratings of chance of recurrence $(r=-0.219, P=0.064$; $r=-0.438, P=000)$, prognosis at time of participation in this study $(r=-0.283, P=0.016 ; r=-0.339, P=0.004$, and staging data $(r=-0.223, P=0.059 ; r=-0.380, P=0.001)$.

\section{Discussion}

The results of this study do not confirm the basic premise of the discrepancy congruence model, which posits that incongruence between a cancer patient and a spouse or a partner is tantamount to poor outcomes for the cancer patient. With respect to coping efficacy, the low correlation between the wives' and husbands' perspectives on the coping efficacy of the wives would indicate little correspondence between their perspectives. Therefore, the coping discrepancy model would not be confirmed because the assumption in the congruence model is that incongruence is a difference based on exactly the same construct. In contrast, the WSEC and HSEC in this study may represent different perspectives based on somewhat different information used to make judgments about coping efficacy. Thus, there was no relationship between absolute differences of wives' and husbands' rating of coping efficacy and the wives' adjustment to cancer. Moreover, follow-up analyses comparing husbands who overestimated with those underestimated their wives' coping efficacy revealed no differences on the measure of wives' adjustment.

Although speculative, perhaps husbands and wives access different information or schemas ${ }^{21}$ in making judgments about coping. According to self-efficacy theory, ${ }^{22}$ wives may use prior experiences (eg, coping with other stressors) and their internal states (eg, worry or anxiety) to assess their ability to cope with cancer, whereas husbands may rely on their estimates of their wives' prior coping efforts as well as other information based on observation of behaviors, medical information (eg, stage, prognosis, and probability of recurrence), and their conceptions of cancer as a disease. Thus, 
wives' judgments may be based on internal, personal, and subjective information, whereas husbands may use external, observable, and objective information such as medical data. Thus, although speculative at this point, these may be somewhat different but complementary perspectives.

A different approach to discrepancy may be accomplished by having wives rate themselves on coping as they think that their husbands might have rated them. This "reflected efficacy" could then be compared with the husbands' rating of their wives and the wives' own ratings to determine where differences occur. Perhaps, testing discrepancy and additive models using reflective efficacy ratings would add to our knowledge about how couples cope. These speculations about the sources of coping efficacy judgments and reflective efficacy could be explicated in future research efforts.

The additive and multiplicative models did relate to wives' adjustment and reinforce that the combination of perspectives rather than discrepancy is related to adjustment to cancer. In addition, the mediation analyses confirmed that the additive model fully accounted for the relationship between functional status and adjustment and, therefore, perhaps is a more proximal cause of differences in adjustment than functional status. Reinforcing the findings from the additive mediation model are the results of the mediation analysis in which WSEC and HSEC were entered as dual mediators.

Collectively, these results indicate that coping congruence may be less critical than complementarity. The data indicate that more is better, that is higher collective coping efficacy scores are associated with better adjustment. Thus, interventions to elevate both wives' coping and husbands' perceptions of wives' coping would lead to improvements in adjustment as opposed to reducing all incongruences, which may be the goal of the coping congruence model.

Several limitations of this study need to be noted and also may provide some impetus for future research in the area of coping efficacy and adjustment to cancer. First, the sample in this study was racially homogeneous, mostly middle class, and educated. Although these characteristics may represent accurately the area in which the data were gathered, they may reflect people who can afford medical treatment and may be aware of the risk factors and issues surrounding the disease of breast cancer. The catchment area for the clinical oncology practice and the hospital includes a large regional area of two states. Whereas the only city of any size in that area has a $\sim 35 \%$ ethnic minority population, the larger region, in which over a million people reside, is rural and White. Thus, the percentage of ethnic minorities in the sample accurately reflected the population from which the sample was derived. However, this does not diminish the concerns about the external validity of the findings. Second, a longitudinal design would have some advantages over the cross-sectional design used in this study. In a longitudinal design, the pattern of the wives' and husbands' coping efficacy expectations over time could be modeled and related to adjustment. Moreover, in a longitudinal design, mediation analyses would provide a stronger case for making causal arguments for the relationship between coping and adjustment.

\section{Conclusion}

This study suggests that more efficacious breast cancer patients with respect to coping are better adjusted to their disease than those who report having lower levels of coping efficacy. Additionally, husbands have a unique perspective on their wives' coping that contributed to their adjustment to cancer, albeit a small but positive contribution. In order to more clearly understand the husbands' basis for judging wives' coping and contributions to their wives' adjustment, future research may benefit from focusing on the sources of coping efficacy judgments made by husbands and wives and on the couple as the primary unit of study.

\section{Acknowledgments}

The authors would like to thank the wives with breast cancer and their husbands who participated in this study, as well as the physicians and staff of Michiana Hematology-Oncology, the Northern Indiana Cancer Research Consortium, and Memorial Hospital's Regional Cancer Center, South Bend, Indiana.

\section{Disclosure}

The authors report no conflicts of interest in this work.

\section{References}

1. Brandão T, Pedro J, Nunes N, Martins MV, Costa ME, Matos PM. Marital adjustment in the context of female breast cancer: a systematic review. Psychooncology. 2017;26(12):2019-2029.

2. Kayser K, Acquati C, Reese JB, Mark K, Wittmann D, Karam E. A systematic review of dyadic studies examining relationship quality in couples facing colorectal cancer together. Psychooncology. 2018;27(1):13-21.

3. Regan TW, Lambert SD, Kelly B, Falconier M, Kissane D, Levesque JV. Couples coping with cancer: exploration of theoretical frameworks from dyadic studies. Psychooncology. 2015;24(12):1605-1617.

4. Kuijer RG, Ybema JF, Buunk BP, et al. Active engagement, protective buffering, and overprotection: three ways of giving support by intimate partners of patients with cancer. J Soc Clin Psychol. 2000;19(2):256-275.

5. Rottmann N, Hansen D, Larsen P, et al. Dyadic coping within couples dealing with breast cancer: a longitudinal, population-based study. Health Psychol. 2015;34(5):486-495. 
6. Traa MJ, De Vries J, Bodenmann G, Den Oudsten BL. Dyadic coping and relationship functioning in couples coping with cancer: a systematic review. Br J Health Psychol. 2015;20(1):85-114.

7. Berg C, Wiebe D, Butner J, et al. Collaborative coping and daily mood in couples dealing with prostate cancer. Psychol Aging. 2008;23(3):505-516.

8. Basinger E. Explicating the appraisal dimension of the communal coping model. Health Commun. Epub 2017 Mar 29.

9. Lewis MA, McBride CM, Pollak KI, Puleo E, Butterfield RM, Emmons KM. Understanding health behavior change among couples: an interdependence and communal coping approach. Soc Sci Med. 2006;62(6):1369-1380.

10. Barnoy S, Bar-TalY, Zisser B. Correspondence in informational coping styles: how important is it for cancer patients and their spouses? Pers Indiv Differ. 2006;41(1):105-115.

11. Li Q, Loke A. A systematic review of spousal couple-based intervention studies for couples coping with cancer: direction for the development of interventions. Psychooncology. 2014;23(7):731-739.

12. Ben-Zur H, Gilbar O, Lev S. Coping with breast cancer: patient, spouse, and dyad models. Psychosom Med. 2001;63:32-39.

13. Romero C, Lindsay JE, Dalton WT, Nelson DV, Friedman LC. Husbands' perceptions of wives' adjustment to breast cancer: the impact on wives' mood. Psychooncology. 2008;17(3):237-243.
14. Corcoran K, Fischer J. Measures for Clinical Practice. New York: The Free Press; 1987.

15. Merluzzi TV, Martinez Sanchez M. Assessment of self-efficacy and coping with cancer: development and validation of the Cancer Behavior Inventory. Health Psychol. 1997;16(2):163-170.

16. Karnofsky DA, Abelmann WH, Craver LF. The use of nitrogen mustards in the palliative treatment of carcinoma. Cancer. 1948;1:634-656.

17. Grieco A, Long CJ. Investigation of the Karnofsky Performance Status as a measure of quality of life. Health Psychol. 1984;3(2):129-142.

18. Viet CT, Ware JE. The structure of psychological distress and wellbeing in general populations. J Consult Clin Psychol. 1983;51(5): 730-742.

19. Derogatis LR, Derogatis MF. The Psychosocial Adjustment to Illness Scale: Administration, Scoring, and Procedures Manual-II. Towson: Clinical Psychometric Research; 1990.

20. Zhang Z, Wang L. Methods for mediation analysis with missing data. Psychometrika. 2013;78(1):154-184.

21. Rudy TE, Merluzzi TV. Recovering social cognitive schemas. In: Kendall PC, editor. Advances in Cognitive Behavioral Research and Therapy. Vol. 3. New York: Academic Press; 1984:61-102.

22. Bandura A. Self-Efficacy the Exercise of Control. New York: W.H. Freeman; 1997.
Cancer Management and Research

\section{Publish your work in this journal}

Cancer Management and Research is an international, peer-reviewed open access journal focusing on cancer research and the optimal use of preventative and integrated treatment interventions to achieve improved outcomes, enhanced survival and quality of life for the cancer patient. The manuscript management system is completely online and includes
Dovepress

a very quick and fair peer-review system, which is all easy to use. Visit http://www.dovepress.com/testimonials.php to read real quotes from published authors. 